\title{
Correlates of long-term physical activity adherence in women
}

\author{
Haichun Sun ${ }^{\mathrm{a}, *}$, Cheryl A. Vamos ${ }^{\mathrm{b}}$, Sara S.B. Flory ${ }^{\mathrm{a}}$, Rita DeBate ${ }^{\mathrm{b}}$, \\ Erika L. Thompson ${ }^{\mathrm{b}}$, Jennifer Bleck ${ }^{\mathrm{b}}$ \\ ${ }^{a}$ Department of Teaching and Learning, College of Education, University of South Florida, Tampa, FL 33620, USA \\ ${ }^{\mathrm{b}}$ Department of Community and Family Health, College of Public Health, University of South Florida, Tampa, FL 33612, USA
}

Received 14 March 2015; revised 23 June 2015; accepted 25 October 2015

Available online 12 January 2016

\begin{abstract}
Background: Little is known about the factors that may influence women's adherence to moderate-to-vigorous physical activity (MVPA) using longitudinal data. The purpose of this study was to examine the correlates of long-term physical activity (PA) participation among women.

Methods: Female data from Waves I, III, and IV $(n=5381)$ of the National Longitudinal Study of Adolescent to Adult Health (Add Health) were used for the analysis. The outcome of PA adherence was operationalized as (1) consistently physically active (at least 5 instances during the week) in both Waves III and IV (during adulthood), and (2) consistently not physically active or only physically active in either Wave III or IV. Predictor variables from Wave I (during adolescence) included race/ethnicity, PA level, self-perception of being physically fit, general health status, attempt to change weight, parents' income level, parents' education, well-being, depression, access to PA resources, days of physical education (PE), and grade level. Crude and adjusted logistic regression models were utilized to estimate the adjusted odds ratio (aOR) and 95\% confidence interval $(95 \% \mathrm{CI})$ for the outcome variable.

Results: PA levels during adolescence significantly predicted PA adherence (aOR $=1.67,95 \% \mathrm{CI}: 1.35-2.05)$. Additionally, wanting to lose weight $(\mathrm{aOR}=1.49,95 \% \mathrm{CI}: 1.20-1.85)$, using fitness center in the neighborhood (aOR $=1.29,95 \% \mathrm{CI}: 1.05-1.58)$, and having 5 days of PE a week $(\mathrm{aOR}=1.48,95 \% \mathrm{CI}: 1.09-2.02)$ were significant predictors. Women who did not perceive being physically fit $(\mathrm{aOR}=0.65,95 \% \mathrm{CI}: 0.44-0.95)$ and Black, non-Hispanics $(\mathrm{aOR}=0.60,95 \% \mathrm{CI}$ : $0.44-0.82)$ were less likely to adhere to PA.

Conclusion: The findings suggested that physically active adolescents were more likely to become active adults. Future research should address interventions (e.g., PE program, community resources) that may promote lifetime PA in women, with the goal of decreasing morbidity and mortality. (C) 2017 Production and hosting by Elsevier B.V. on behalf of Shanghai University of Sport. This is an open access article under the CC BY-NC-ND license (http://creativecommons.org/licenses/by-nc-nd/4.0/).
\end{abstract}

Keywords: Females; Longitudinal; Moderate-to-vigorous physical activity; Social ecological frameworks

\section{Introduction}

The proportion of children who are obese or overweight has significantly increased over the past decade. ${ }^{1}$ In 2011-2012, $31.8 \%$ of children ( $95 \%$ confidence interval (CI): $29.1 \%-$ $34.7 \%$ ) in the US aged 2-19 years were either overweight or obese, and $16.9 \%$ of the youth (CI: $14.9 \%-19.2 \%$ ) were obese. ${ }^{2}$ Rising rates of obesity have dangerous long-term effects since $40 \%-70 \%$ of obese children will become obese adults when they grow up. ${ }^{3}$

Sedentary activity is one of the major factors identified as contributing to the obesity crisis. Research has also revealed

Peer review under responsibility of Shanghai University of Sport.

* Corresponding author.

E-mail address: sun@usf.edu (H. Sun) numerous associations between physical activity (PA) and health outcomes. For example, PA can reduce risk of early death, cardiovascular disease, stroke, hypertension, type 2 diabetes, and depression and increase cognitive function. ${ }^{4,5}$ While the public health significance of PA is well documented, a recent report showed that only $18.4 \%$ of adolescents meet current PA guidelines for aerobic activities; this is even lower for females at $11.4 \%{ }^{6}$ Meanwhile, only $21 \%$ of U.S. adults participated in enough aerobic and muscle strengthening exercises to meet guidelines in 2011, with men more likely than women to meet these guidelines. ${ }^{6}$ In addition, a previous study revealed that PA stability over 22 years from youth to adulthood was low and not significant, whereas body mass index (BMI) stability was moderately strong. ${ }^{7}$ Specifically, only $16 \%$ of physically active youths became active adults and $83 \%$ of overweight youths remained overweight as 
adults, while $85 \%$ of overweight adults were not overweight youths.

Research has suggested that participation in PA also declines across the lifespan and the sharpest decrease occurs during the transition from late adolescence to early adulthood. ${ }^{8}$ Using the National Longitudinal Study of Adolescent to Adult Health (Add Health) data in Waves I and III, a study examined trends in achieving 5 or more sessions of moderate-to-vigorous physical activity (MVPA) per week across the transition period from adolescence to young adulthood. ${ }^{9}$ Results showed that the majority of men (52.3\%) and women (70.7\%) did not achieve this amount of PA across both periods. Essentially, only very few (4.4\%) among those who achieved 5 or more weekly sessions of MVPA continued to achieve these recommended amounts of PA. A prospective longitudinal study further indicated that women's PA significantly decreased from high school to college and suggested that the transition from high school to college is a critical time to promote PA among women. ${ }^{10}$

As highlighted in these reports, women are not only less likely to participate in PA compared to men but also less likely to consistently engage in PA over the years than men. Nonetheless, PA is especially important to women since it can influence future generations due to health status during pregnancy or modeling of behaviors to offspring. ${ }^{11,12}$ In order to provide effective interventions for prompting PA, studies have been conducted to identify factors that influence women's PA participation. Much of the past research has used social-ecological frameworks for a more comprehensive understanding of PA behavior. Such frameworks allow for the integration of the multifaceted influence of individual, social and policy, and environmental factors on participation in PA. ${ }^{13}$

A range of individual factors including demographic, biomedical, and psychological factors influence participation in PA for young women. Specifically, research has suggested that age, ethnicity/race, education, socio-economic status (SES), cardiovascular disease/cancer, BMI, self-reported health status, mental health/depression, attitude, self-efficacy, enjoyment, values, and beliefs can influence women's PA. ${ }^{14,15}$ Social factors specifically among adolescent young women that influence PA include social support from peers, family status, ${ }^{16}$ family cohesion, parent-child communication, and parent engagement. ${ }^{17}$ Additionally, school-organized sports program and physical education (PE) are important factors in encouraging and sustaining PA behaviors. ${ }^{18,19}$ Environmental factors include the physical environment, neighborhood design, and structural issues that influence women's decision to become physically active. ${ }^{20}$ Moreover, previous studies have reported that landscape diversity, higher street connectivity, and lower crime are associated with women's PA participation. ${ }^{21}$ A previous study also found that high crime level was significantly associated with a decrease in weekly MVPA among 17,766 U.S. adolescents enrolled in middle and high schools using Add Health data. ${ }^{22}$

Although we have known that aforementioned factors, alone or in combination, could impact women's decision about PA engagement, the majority of the literature evaluates PA across age groups using cross-sectional data or confines longitudinal data to short time windows. ${ }^{14-16,23,24}$ Research on the topic of PA, particularly as it relates to factors that contribute to PA adherence in women, is scarce. ${ }^{25}$ Furthermore, the limited literature is mixed as to factors that are associated with women's PA adherence over time. White and colleagues ${ }^{25}$ suggested that women's enjoyment, length of the PA bout, setting, self-efficacy, and program tailoring may be factors that influence women's adherence to PA..$^{25}$ In a longitudinal analysis, Hearst et al. ${ }^{24}$ examined how factors are associated with MVPA among adolescents ( $n=578$, aged $10-16$ years at baseline) from a socialecological model. They found that baseline MVPA and perceived barriers significantly predicted girls' MVPA at the 24-month follow-up. Additionally the results suggested that self-efficacy did not emerge as a significant predictor for girls in their sample (aged 10-16 years), although self-efficacy has been found to be the only consistently positively associated variable with MVPA changes among the youth. ${ }^{26}$

In summary, previous studies have suggested that the relationship between individual, social, and physical environmental factors and PA adherence in women has been inconclusive and studies longer than 2 years are needed because these factors may change over time. ${ }^{24,25}$ Thus, the purpose of the present study was to explore the correlates of long-term PA adherence among women using nationally representative longitudinal data. The topic is salient as Healthy People 2020 aims to increase the proportion of adolescents and adults who meet current national PA guidelines for aerobic activities and for muscle-strengthening activities. ${ }^{27}$ Findings have the potential to provide evidence-based strategies for future PA intervention or program design.

\section{Methods}

\subsection{Study design and population}

This study consisted of a secondary data analysis using data from Add Health. Add Health is a longitudinal study of a nationally representative cohort of adolescents that aims to identify social, behavioral, and biological linkages across the life course.$^{28}$ The study began in 1994 with adolescents in the 7 th through 12 th grades. A systematic sampling method was used to recruit 80 high schools that were representative of schools in the US with regard to region, urbanicity, size, type (e.g., zip code, public or private school), and ethnicity. Each high school identified a 7th grade feeder school, resulting in a total of 132 participating schools across 80 communities. After an initial in-school questionnaire, students were stratified by grade and sex. Subsequently, approximately 17 students from each stratum, for a total of about 200 adolescents per community school pairing, were randomly selected for an in-home interview. At Wave I a total of 20,745 adolescents were interviewed. There have been 3 subsequent waves of interviews. The sample for this current study was derived from Waves I (19941995), III (2001-2002), and IV (2008-2009). Wave II (1996) data were not used for this analysis due to the time proximity of the measure of PA in Wave I and due to the amount of missing data at this wave.

In Wave I, 10,480 of the participants were women. Among them, 7038 women completed all 3 waves we are interested in 
and only 6682 women had sample weights available. Participants with missing information regarding PA, any covariates, or survey weights were excluded from the analysis, leaving a final sample size of 5381. When assessing the missing data, it appeared that parental education and PE were the 2 predictors producing the most missing data. The majority of participants were White-non-Hispanics (67.9\%). This study was approved by and received exempt status from the University of South Florida Institutional Review Board.

\subsection{Measures}

\subsubsection{PA outcome}

PA level was assessed using 6 items each from Waves III and IV. The PA questions followed the following format: "In the past 7 days, how many times did you ..." perform a specified type of PA. Types of activities included: bicycle, skateboard, dance, hike, hunt, yard work, roller blade, roller skate, downhill ski, snow board, racquet sports, and aerobics; strenuous team sports such as football, soccer, basketball, lacrosse, rugby, field hockey, or ice hockey; individual sports such as running, wrestling, swimming, cross-country skiing, cycle racing, or martial arts; and activities such as gymnastics, weight lifting, strength training, golf, fishing or bowling, softball or baseball. These activities are considered as MVPA with regard to intensity level. The participants then listed the number of times they participated in any of those activities in the past 7 days for each question. These numbers of activity participation instances were then summed to produce an overall number of instances the participants engaged in PA during that week.

Each participant was considered to have a high PA level if she reported doing any type of the activities 5 or more instances in the past 7 days at each wave, respectively. This method to operationalize PA using the Add Health dataset is consistent with other reports using these data. ${ }^{9,22}$ The outcome of PA adherence was operationalized as (1) consistently physically active (at least 5 instances during the week) in both Waves III and IV, and (2) consistently not physically active or only physically active in either Wave III or IV.

\subsubsection{Predictor variables}

Predictor variables were selected based upon socialecological framework including 3 levels: (1) individual factors, (2) social/organizational factors, and (3) environmental factors.
The variables ascertained for these levels were assessed during Wave I (Fig. 1) when participants were in the 7th-12th grades.

The first category was the individual level. The PA level at Wave I was measured and operationalized in the same fashion as Waves III and IV for the outcome variable. It was dichotomized as greater than or equal to 5 instances of activity and less than 5 instances of activity (referent category). Race/ethnicity was operationalized as White-non-Hispanic, Hispanic, Blacknon-Hispanic, Asian, and other. The total parent income level was categorized as less than USD20,000, between USD20,000 and USD59,000, and USD60,000 or greater per year. The highest education level for either the mother or father was used as the parent education level, which was divided into less than high school, high school, some college, and college. The grade level (Grades 7-12) of the participants in Wave I was also included as a predictor variable to control for differences in the measure of the baseline variables.

The participants were also asked to rate the extent to which they agree/disagree with the statement, "Do you consider yourself physically fit?" The responses were categorized as "strongly agree", "agree", "neither agree nor disagree", and "disagree/ strongly disagree". The latter 2 categories of "disagree" and "strongly disagree" were combined due to low frequencies within these categories. Self-reported general health status was categorized as "excellent", "very good", "good", and "fair/ poor". Due to the low frequencies in the "fair" and "poor" categories, these separate categories were combined. The depression score was a sum score derived from the Center for Epidemiologic Studies Depression scale (CES-D). ${ }^{29}$ It was measured on a Likert scale of 0 (never or rarely) to 3 (most of the time or all the time). The participants were asked by questions such as "bothered by things", "could not shake off the blues", etc. The well-being score was a sum score derived from questions regarding personality and was measured on a Likert scale of 1 (not at all) to 5 (very much). ${ }^{30}$ Sample questions are "have a lot of good qualities" and "have a lot to be proud of". Finally, the variable of wanting to change weight was measured by asking participants the question: "Are you trying to lose, gain, or stay the same weight?" The answers were categorized as trying to stay the same weight, trying to lose weight, trying to gain weight, or not trying to do anything about it.

The second category of variables was from the social/ organizational level; these include school-related variables. The

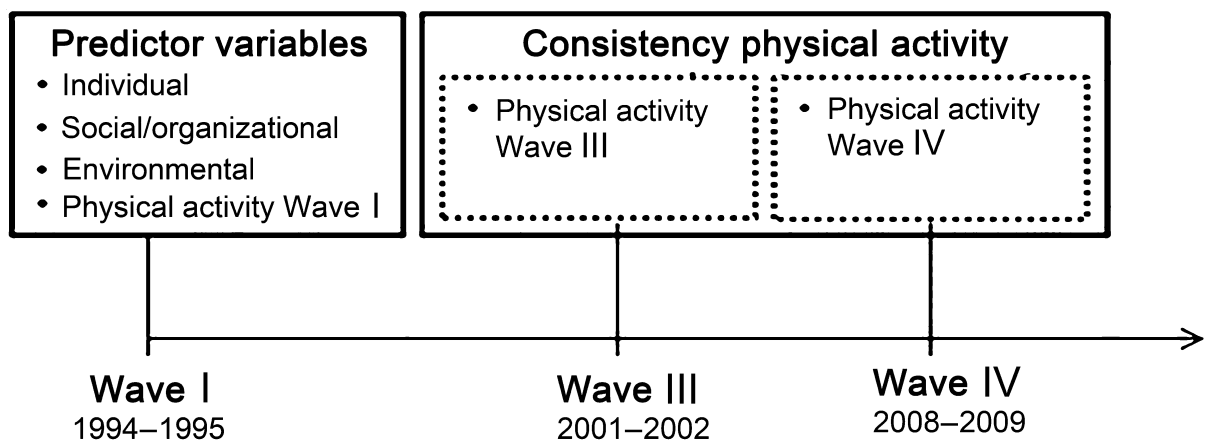

Fig. 1. Schematic of the study design and variables included. 
participants were asked if they were taught exercise in a school setting and were taught about the problems of being overweight in a school setting; these variables were dichotomized as "yes" or "no". The number of days a week students had PE in school was categorized as 5 days, 1-4 days, 0 day, and no answer. Note, however, that many students reported not having PE (i.e., no answer) due to the time frame the questionnaire was administered (i.e., summer).

The third category of variables was the environmental level. The participants were asked if they used physical fitness centers in their neighborhood and felt safe in their neighborhood; these were dichotomized as "yes" or "no".

\subsubsection{Data analysis}

Descriptive characteristics of the sample including PA frequencies and prevalence of structural predictors were examined. $\chi^{2}$ tests were used to test for differences in consistency of PA with predictor variables. A logistic regression model weighted for the survey weights in this sample was employed to investigate the association between consistent $\mathrm{PA}$ and predictor variables. Crude odds ratios (OR) and 95\%CI for each variable and the outcome of PA were calculated. Adjusted OR (aOR) and $95 \% \mathrm{CI}$ were determined and adjusted for each of the structural variables, individual race, and individual age. All analyses were conducted in SAS Version 9.3 (SAS Institute Inc., Cary, NC, USA).

\section{Results}

Table 1 suggests that the majority of participants in Wave I had parents with at least a high school education and income between USD20,000 and USD59,000 per year. There was an even distribution for grade levels for participants during Wave I. With regard to individual health characteristics, most participants agreed or strongly agreed that they were physically fit, reported either very good or excellent general health status, and wanted to lose weight. The mean depression and well-being scales for the population were 11.56 and 11.81, respectively. In Wave 1, more than half of participants were not engaged in MVPA for more than 5 instances in a week. Among the participants, $25.92 \%$ reported being consistently physically active.

Most participants were taught about exercise in school $(92.66 \%)$, while fewer reported learning about the problems of being overweight (59.04\%). Nearly $62.65 \%$ of the participants did not report being currently taught PE in school; however, this could be due to the fact that many participants were interviewed during the summer. Sixteen point zero two percent of the participants reported having 0 day of $\mathrm{PE}, 14.18 \%$ had 5 days of $\mathrm{PE}$, and $7.15 \%$ had $1-4$ days of PE. Finally, some participants reported using a fitness center $(17.19 \%)$ in their neighborhood and most of them felt safe in their neighborhood (89.85\%).

OR were used to examine the independent association between each predictor variable and the odds of being consistently physically activity. Specifically, regarding the individual level predictors, being physically active during Wave I had 2 times the odds of being consistently physically active later in life. Black-nonHispanics were less likely to be consistently physically active compared to White-non-Hispanics. Additionally, participants with parents who had higher incomes and high education statuses were more likely to be consistently physically active. However, variables for reducing the likelihood of being consistently physically active included: neither agreeing nor disagreeing to being physically fit, disagreeing or strongly disagreeing to being physically fit, agreeing to being physically fit, a "good" general health status, a "fair/poor" general health status, and wanting to lose weight (Table 2).

In the crude logistic regression model, according to factors at the social/organization level, being taught PE for 5 days during the school week was significantly associated with being more likely to be consistently physically active later in life. Both predictors at the environmental level - using fitness center and feeling safe in the neighborhood-increased the likelihood of consistent PA.

Adjusted models included all predictor variables previously listed and aOR are reported (Table 2). Participants who were physically active in Wave I were more likely to be consistently physically active later in life $(\mathrm{aOR}=1.67,95 \% \mathrm{CI}: 1.36-2.05)$. Other individual level predictors for increasing the likelihood of being consistently physically active included: higher parent income; higher parent education; and wanting to lose weight in Wave I. In contrast, Black-non-Hispanics, participants who disagreed or strongly disagreed to being physically fit, and participants who neither agreed nor disagreed to being physically fit were less likely to remain consistently physically active.

At the social/organizational level, having PE 5 times a week remained statistically significant $(\mathrm{aOR}=1.48,95 \% \mathrm{CI}$ : 1.09 2.02). At the environmental level, the effect of feeling safe in the neighborhood was attenuated to non-significant, but using a fitness center in the neighborhood remained statistically significant $(\mathrm{aOR}=1.29,95 \% \mathrm{CI}: 1.05-1.58)$.

\section{Discussion}

The purpose of the present study was to explore the correlates of long-term PA adherence among women using nationally representative longitudinal data. Previous studies revealed inconclusive findings regarding the consistency of PA levels across age groups. ${ }^{7,31}$ Research has further indicated that there might be heterogeneous groups within these larger samples that limit firm conclusion to be made, and that there might be a specific determinant that influences the consistency of PA at different time periods. ${ }^{26,31}$ Therefore, it is critical to identify factors that impact PA adherence in a relatively homogeneous groupteenage females (Wave I) - and that have significant life course implications for the individual and potential offspring.

\subsection{Individual level}

The findings suggest that physically active female adolescents are more likely to participate in PA when they become adults. This association has also been demonstrated in PA tracking studies. In a 21-year tracking study, Telama et al. ${ }^{32}$ concluded that high levels of PA at ages 9-18, especially when continuous, significantly predicted high levels of adult PA. Likewise, Trudeau and colleagues ${ }^{19}$ indicated that currently physically active females were more likely to have participated 
Table 1

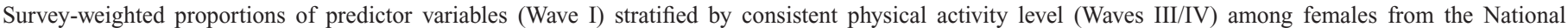
Longitudinal Study of Adolescent Health.

\begin{tabular}{|c|c|c|c|}
\hline Predictor variable & Consistently active & Not consistently active & Total \\
\hline Total & $25.92(1.02)$ & $74.08(1.02)$ & \\
\hline \multicolumn{4}{|l|}{ Individual level } \\
\hline \multicolumn{4}{|l|}{ Physical activity } \\
\hline Yes ( $\geq 5$ instances) & $19.35(0.92)$ & $43.77(1.15)$ & $43.57(1.04)$ \\
\hline No (<5 instances) & $6.51(0.53)$ & $30.37(1.18)$ & $56.43(1.04)$ \\
\hline \multicolumn{4}{|l|}{ Race/ethnicity } \\
\hline White-non-Hispanic & $19.26(1.23)$ & $48.60(2.22)$ & $67.86(2.87)$ \\
\hline Hispanic & $2.60(0.40)$ & $8.55(1.38)$ & $11.15(1.70)$ \\
\hline Black-non-Hispanic & $2.49(0.40)$ & $12.68(1.81)$ & $15.17(2.09)$ \\
\hline Asian & $0.78(0.22)$ & $2.22(0.54)$ & $3.00(0.72)$ \\
\hline Other & $0.74(0.16)$ & $2.08(0.33)$ & $2.82(0.39)$ \\
\hline \multicolumn{4}{|l|}{ Parent education } \\
\hline Less than high school & $2.21(0.34)$ & $8.49(0.95)$ & $10.69(1.18)$ \\
\hline High school & $5.22(0.45)$ & $22.01(1.21)$ & $27.24(1.28)$ \\
\hline Some college & $7.70(0.53)$ & $22.31(0.95)$ & $30.01(1.13)$ \\
\hline College & $10.74(0.91)$ & $21.32(1.40)$ & $32.06(2.01)$ \\
\hline \multicolumn{4}{|l|}{ Parent income (per year) } \\
\hline Less than USD20,000 & $6.29(0.47)$ & $22.61(1.42)$ & $28.91(1.56)$ \\
\hline USD20,000-USD59,000 & $11.26(0.62)$ & $35.51(1.16)$ & $46.76(1.31)$ \\
\hline USD60,000 or more & $8.31(0.71)$ & $16.02(1.18)$ & $24.33(1.65)$ \\
\hline \multicolumn{4}{|l|}{ Grade } \\
\hline 7 th & $5.09(0.71)$ & $13.27(1.60)$ & $18.35(2.16)$ \\
\hline 8 th & $4.33(0.62)$ & $12.29(1.54)$ & $16.63(1.96)$ \\
\hline 9th & $4.76(0.54)$ & $12.48(0.99)$ & $17.24(1.31)$ \\
\hline 10 th & $4.16(0.45)$ & $13.15(1.01)$ & $17.31(1.25)$ \\
\hline 11 th & $3.86(0.41)$ & $11.32(0.91)$ & $15.18(1.10)$ \\
\hline 12 th & $3.67(0.42)$ & $11.62(0.93)$ & $15.29(1.12)$ \\
\hline \multicolumn{4}{|l|}{ Self-reported physically fit } \\
\hline Strongly agree & $6.19(0.48)$ & $12.62(0.73)$ & $18.81(0.86)$ \\
\hline Agree & $12.34(0.69)$ & $33.57(0.83)$ & $45.91(0.94)$ \\
\hline Neither agree nor disagree & $4.84(0.40)$ & $17.25(0.74)$ & $22.10(0.81)$ \\
\hline Disagree or strongly disagree & $2.49(0.26)$ & $10.70(0.70)$ & $13.18(0.76)$ \\
\hline \multicolumn{4}{|l|}{ Self-reported general health } \\
\hline Excellent & $7.50(0.57)$ & $17.09(0.76)$ & $24.59(0.88)$ \\
\hline Very good & $11.35(0.66)$ & $29.63(0.88)$ & $41.00(0.94)$ \\
\hline Good & $5.72(0.43)$ & $21.18(0.90)$ & $26.90(0.92)$ \\
\hline Fair/poor & $1.29(0.20)$ & $6.24(0.61)$ & $7.51(0.63)$ \\
\hline \multicolumn{4}{|l|}{ Wanting to change weight } \\
\hline Stay the same weight & $8.35(0.52)$ & $26.34(0.90)$ & $34.69(0.98)$ \\
\hline Lose weight & $13.16(0.74)$ & $33.56(1.13)$ & $46.72(1.10)$ \\
\hline Gain weight & $1.31(0.18)$ & $5.47(0.46)$ & $6.78(0.49)$ \\
\hline Not trying to do anything & $3.04(0.36)$ & $8.77(0.65)$ & $11.81(0.82)$ \\
\hline Depression (Scale 0-30) & $11.23(10.81,11.64)$ & $12.09(11.84,12.34)$ & $11.56(11.14,11.98)$ \\
\hline Well-being (Scale 0-30) & $11.47(11.28,11.66)$ & $11.85(11.73,11.96)$ & $11.81(11.63,12.00)$ \\
\hline \multicolumn{4}{|l|}{ Social/organizational level } \\
\hline \multicolumn{4}{|l|}{ Physical education taught in school } \\
\hline 0 day & $3.26(0.37)$ & $12.76(1.23)$ & $16.02(1.39)$ \\
\hline $1-4$ days & $1.99(0.35)$ & $5.16(0.76)$ & $7.15(0.99)$ \\
\hline 5 days & $4.18(0.48)$ & $10.00(1.02)$ & $14.18(1.30)$ \\
\hline No answer & $16.43(1.02)$ & $46.22(1.45)$ & $62.65(1.95)$ \\
\hline \multicolumn{4}{|l|}{ Taught exercise in school } \\
\hline Yes & $24.28(1.02)$ & $68.38(1.11)$ & $92.66(0.76)$ \\
\hline No & $1.58(0.26)$ & $5.76(0.70)$ & $7.34(0.76)$ \\
\hline \multicolumn{4}{|c|}{ Taught problems of overweight in school } \\
\hline Yes & $15.58(1.03)$ & $43.45(1.49)$ & $59.04(1.86)$ \\
\hline No & $10.28(0.76)$ & $30.69(1.46)$ & $40.96(1.86)$ \\
\hline \multicolumn{4}{|l|}{ Environmental level } \\
\hline \multicolumn{4}{|l|}{ Fitness center in neighborhood } \\
\hline Yes & $5.47(0.63)$ & $11.72(0.79)$ & $17.19(1.24)$ \\
\hline No & $20.39(0.87)$ & $62.42(1.32)$ & $82.81(1.24)$ \\
\hline Feeling safe in neighborhood & & & \\
\hline Yes & $23.84(1.04)$ & $66.01(1.02)$ & $89.85(0.80)$ \\
\hline No & $2.02(0.23)$ & $8.13(0.70)$ & $10.15(0.80)$ \\
\hline
\end{tabular}

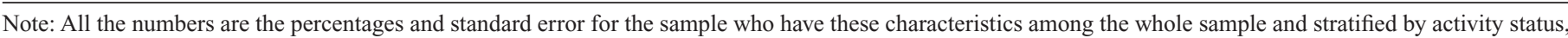

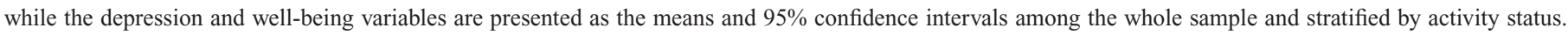


Table 2

Logistic regression models predicting consistent physical activity level (Waves III and IV) for social environment, built environment, and individual predictors (Wave I) among females in the National Longitudinal Study of Adolescent Health $(n=5381)$

\begin{tabular}{|c|c|c|}
\hline Predictor variable & $\begin{array}{l}\text { Crude odds ratio } \\
(95 \% \mathrm{CI})\end{array}$ & $\begin{array}{l}\text { Adjusted odds ratio } \\
(95 \% \mathrm{CI})\end{array}$ \\
\hline \multicolumn{3}{|l|}{ Individual level } \\
\hline \multicolumn{3}{|l|}{ Physical activity } \\
\hline Yes ( $\geq 5$ instances) & $2.06(1.69-2.52)$ & $1.67(1.36-2.05)$ \\
\hline No (<5 instances) & 1.00 (referent) & 1.00 (referent) \\
\hline \multicolumn{3}{|l|}{ Race/ethnicity } \\
\hline White-non-Hispanic & 1.00 (referent) & 1.00 (referent) \\
\hline Hispanic & $0.77(0.58-1.01)$ & $0.94(0.69-1.28)$ \\
\hline Black-non-Hispanic & $0.50(0.37-0.67)$ & $0.60(0.44-0.82)$ \\
\hline Asian & $0.89(0.58-1.36)$ & $0.87(0.56-1.35)$ \\
\hline Other & $0.90(0.57-1.41)$ & $0.94(0.63-1.43)$ \\
\hline \multicolumn{3}{|l|}{ Parent income (per year) } \\
\hline Less than USD20,000 & 1.00 (referent) & 1.00 (referent) \\
\hline USD20,000-USD59,000 & $1.14(0.93-1.40)$ & $0.98(0.78-1.22)$ \\
\hline USD60,000 or more & $1.86(1.49-2.33)$ & $1.28(0.98-1.67)$ \\
\hline \multicolumn{3}{|l|}{ Parent education } \\
\hline Less than high school & 1.00 (referent) & 1.00 (referent) \\
\hline High school & $0.91(0.66-1.26)$ & $0.82(0.57-1.17)$ \\
\hline Some college & $1.33(0.99-1.78)$ & $1.12(0.79-1.58)$ \\
\hline College & $1.94(1.46-2.56)$ & $1.40(0.97-2.03)$ \\
\hline \multicolumn{3}{|l|}{ Grade } \\
\hline 7 th & 1.00 (referent) & 1.00 (referent) \\
\hline 8 th & $0.92(0.67-1.26)$ & $0.86(0.62-1.19)$ \\
\hline 9 th & $1.00(0.74-1.35)$ & $0.98(0.73-1.32)$ \\
\hline 10 th & $0.83(0.62-1.10)$ & $0.91(0.70-1.20)$ \\
\hline 11 th & $0.89(0.67-1.19)$ & $1.03(0.77-1.37)$ \\
\hline 12th & $0.83(0.61-1.11)$ & $1.00(0.75-1.32)$ \\
\hline \multicolumn{3}{|l|}{ Self-reported physically fit } \\
\hline Strongly agree & 1.00 (referent) & 1.00 (referent) \\
\hline Agree & $0.75(0.61-0.92)$ & $0.82(0.64-1.05)$ \\
\hline Neither agree/disagree & $0.57(0.45-0.74)$ & $0.71(0.52-0.96)$ \\
\hline Disagree or strongly disagree & $0.47(0.35-0.64)$ & $0.65(0.44-0.95)$ \\
\hline \multicolumn{3}{|l|}{ Self-reported general health } \\
\hline Excellent & 1.00 (referent) & 1.00 (referent) \\
\hline Very good & $0.87(0.70-1.09)$ & $0.93(0.73-1.20)$ \\
\hline Good & $0.62(0.48-0.79)$ & $0.78(0.60-1.03)$ \\
\hline Fair/poor & $0.47(0.31-0.72)$ & $0.68(0.44-1.07)$ \\
\hline Depression (Scale 0-30) & $0.99(0.97-1.00)$ & $1(0.99-1.02)$ \\
\hline Well-being (Scale 0-30) & $0.97(0.95-1.00)$ & $1(0.96-1.04)$ \\
\hline \multicolumn{3}{|l|}{ Wanting to change weight } \\
\hline Stay the same weight & 1.00 (referent) & 1.00 (referent) \\
\hline Lose weight & $1.24(1.02-1.50)$ & $1.49(1.20-1.85)$ \\
\hline Gain weight & $0.76(0.54-1.05)$ & $1.03(0.73-1.45)$ \\
\hline Not trying to do anything & $1.09(0.84-1.42)$ & $1.13(0.86-1.48)$ \\
\hline \multicolumn{3}{|l|}{ Social/organizational level } \\
\hline \multicolumn{3}{|l|}{ Physical education taught in school } \\
\hline 0 day & 1.00 (referent) & 1.00 (referent) \\
\hline $1-4$ days & $1.51(1.00-2.28)$ & $1.36(0.92-2.02)$ \\
\hline 5 days & $1.64(1.19-2.25)$ & $1.48(1.09-2.02)$ \\
\hline No answer & $1.39(1.08-1.80)$ & $1.29(1.00-1.66)$ \\
\hline \multicolumn{3}{|l|}{ Taught exercise in school } \\
\hline Yes & $1.29(0.87-1.92)$ & $1.11(0.73-1.69)$ \\
\hline No & 1.00 (referent) & 1.00 (referent) \\
\hline \multicolumn{3}{|c|}{ Taught problems of overweight in school } \\
\hline Yes & $1.07(0.88-1.31)$ & $1.04(0.84-1.29)$ \\
\hline No & 1.00 (referent) & 1.00 (referent) \\
\hline \multicolumn{3}{|l|}{ Environmental level } \\
\hline \multicolumn{3}{|l|}{ Fitness center in neighborhood } \\
\hline Yes & $1.43(1.17-1.75)$ & $1.29(1.05-1.58)$ \\
\hline No & 1.00 (referent) & 1.00 (referent) \\
\hline \multicolumn{3}{|l|}{ Feeling safe in neighborhood } \\
\hline Yes & $1.46(1.13-1.87)$ & $1.14(0.86-1.50)$ \\
\hline No & 1.00 (referent) & 1.00 (referent) \\
\hline
\end{tabular}

Note: Numbers in bold indicate statistical significance. Abbreviation: $\mathrm{CI}=$ confidence interval in intense organized, non-organized, and recreational PA as children. A longitudinal analysis also suggested that females' baseline MVPA and age were positively and significantly associated with higher levels of MVPA at 24 months. ${ }^{24}$ These findings suggest that health behaviors, such as PA participation, established early in life can become habituated and may influence their PA in future years. ${ }^{24}$ Thus, PA programs and interventions that are specifically designed for children and adolescent girls may play a critical role in forming the foundations for subsequent active lifestyles in future years.

Regression analysis results also suggested that adolescent females' weight concern is a strong predictor of PA adherence. Specifically, "wanting to lose weight" appeared to be an important factor that motivates girls to continually participate in PA. On the one hand, PA has been considered as an important component of interventions to prevent weight gain and to enhance weight loss as well as to maintain weight. ${ }^{33}$ On the other hand, losing weight is one of the most common reasons and a strong motivator for individuals to initiate exercise. ${ }^{34,35}$ Additionally, research also suggested that "losing weight" and "looking better" are stronger motivators for obese than for normal-weight adolescents. ${ }^{36}$ Findings from the present study further demonstrate that weight consciousness or losing weight is an important factor influencing long-term PA behaviors.

In addition to weight concerns, females' perception of being physically fit emerged as a significant predictor for PA adherence. Girls who were uncertain or had a neutral point of view of being physically fit were less likely to become physically active adults. Being physically fit is not only important for health; it reflects individuals' physical fitness level. For instance, maintaining a good physical fitness is impossible without regular exercise or PA. The relationship between physical selfperceptions and PA among school age children and adolescents has been shown in many studies. ${ }^{37,38}$ Children and adolescents' perception of physical fitness was also found reliable and highly correlated to their measured fitness. ${ }^{39}$ More importantly, research has revealed that adolescents' perception of their physical fitness is a crucial factor that impacts their intention toward future PA and subsequent PA patterns. ${ }^{38}$ It might be reasonable to speculate that people who do not have an opinion about their physical fitness may not have the desire to consistently participate in PA. The present study's findings, therefore, might suggest that future interventions need to emphasize the importance of being physically fit and to enhance children and adolescents' awareness of their physical fitness level in order to promote PA adherence.

Moreover, this study found that Black-non-Hispanic females were also less likely to be consistently physically active. Given the fact that Black-non-Hispanic women are one of the least physically active subgroups of the population in the $\mathrm{US}^{40}$ and only $17.3 \%$ of Black-non-Hispanic adults meet the 2008 Physical Activity Guideline, ${ }^{41}$ it is imperative that future PA programs are tailored for Black-non-Hispanic adolescent females to improve their physical fitness with a hope to help them become physically active adults.

Finally, family SES was found to be associated with participants' continuous PA behavior. Specifically, regression analysis 
suggested that participants with higher parent/family income and parental education were more likely to remain physically active. Previous research has suggested that higher family income or high socioeconomic status ${ }^{42}$ and parental education were positively associated with adolescent young females' PA participation. ${ }^{43}$ In addition, another study found strong estimated longitudinal effects of neighborhood SES deprivation on lower PA in Blacks but not Whites. ${ }^{44}$ Our results add to a body of literature showing that PA adherence is also related to family SES; with high SES females more likely to participate in PA over time. Taken together, these findings suggest that girls from low SES backgrounds are at greater risk of the adoption and maintenance of PA behaviors.

\subsection{Social/organizational level}

Results showed that having PE 5 times a week in middle and high schools was significantly correlated to women's long-term PA adherence. The association between PE and PA adherence was also found in previous studies. In their study, Trudeau et al. ${ }^{19}$ found that children (female only, aged 10-12 years) who enrolled in the experimental program of enhanced PE ( $>3$ times per week) were more likely to have a higher frequency of weekly PA when they became adults (aged 35 years) than those who had PE less than 3 times a week.

While National Association of Sport and Physical Education (NASPE), the Centers for Disease Control and Prevention (CDC), and the National Association of State Boards of Education (NASBE) all recommend a minimum of $225 \mathrm{~min}$ per week of PE for middle and high school students, only $7.9 \%$ of middle school and $2.1 \%$ of high schools provided the nationally recommended daily $\mathrm{PE}{ }^{45}$ In addition, a recent survey showed that parents of students in high school were likely to report their children did not take PE at all (18\%) than parents of children in kindergarten through Grade $5(2 \%){ }^{46}$

Although the intervention strategy of a median increase in time dedicated to PE by approximately $10 \%$ has been shown effective for PA promotion with diverse populations and in diverse settings, ${ }^{47} \mathrm{PE}$ classes, recess, and other PA breaks have decreased because many schools are increasing instructional time for science, mathematics, and reading in order to improve students' standards-based test scores. ${ }^{48}$ The results of this study not only reiterate the importance of PE for PA adherence but also reinforce the need for daily PE for middle and high school students to foster long-term PA behavior.

\subsection{Environmental level}

Surprisingly, the effect of feeling safe in the neighborhood was found to be a non-significant predictor of PA adherence. Previous research has found that safety concerns appear to be more influential in females than males with respect to PA participation. ${ }^{49}$ However, as highlighted in previous studies, not all established correlates could be confirmed longitudinally. ${ }^{26}$ It is possible that participants in Wave I moved to other neighborhood communities when they became adults. Thus, safety concerns about the neighborhood in childhood might not be relevant or might not predict their adulthood PA participation.
Our findings further indicate that having a fitness center nearby is important for long-term PA. If there is a fitness center in the neighborhood, adolescent females are more likely to exercise in the center, which might help them to develop sustainable healthy habits. Nevertheless, it might be too early to draw a conclusion with respect to the role of environmental factors in females' PA adherence as findings have not been consistent. For example, Gordon-Larsen et al. ${ }^{22}$ suggested that adolescents' PA pattern was mostly associated with environmental factors such as community recreational center, while Hearst et al. ${ }^{24}$ found no associations between environmental factors (e.g., neighborhood safety and ease of mobility) and adolescent females' PA changes. Further studies are warranted to explore important environmental level factors that may influence women's PA participation and adherence.

The above findings must be interpreted in light of noted study limitations. First, although variables examined in this study were selected based on the socio-ecological framework, some of the key factors may not have been included since this study utilized secondary data and was limited in the availability of those factors. Second, measures such as PA levels are selfreported. Objectively measured PA data are needed in future investigations. Third, in the data analysis, only women who completed all 3 waves with survey weight available were included. Based on this, the final sample then came after removing predictors with missing data. As we analyzed the existing secondary data, these missing data and exclusions were not controlled by us and they were dropped in the analysis because they did not provide the needed information. Nonetheless, cautions should be taken when interpreting and generalizing the findings of this study. Finally, although we used longitudinal data, the participants' ages ranged from adolescents (7th graders) to adults in their early 30 s. Therefore, the findings may not be generalized to other age groups of women.

\section{Conclusion}

Guided by the socio-ecological model, this study examined possible correlates of women's long-term PA adherence. Specifically, the present study has identified several individual, social/organizational, and environmental level factors that could impact women's sustainable PA behaviors. Previous research has suggested that the confounding effects of factors such as education, ethnicity, and SES made it difficult for optimal PA program design for women. ${ }^{25}$ Therefore, these findings assist in highlighting factors across the social-ecological framework which need to be considered during the development of future intervention strategies that aim to support women's PA patterns across the life course.

\section{Acknowledgments}

This research uses data from Add Health, a program project directed by Kathleen Mullan Harris and designed by J. Richard Udry, Peter S. Bearman, and Kathleen Mullan Harris at the University of North Carolina at Chapel Hill, and funded by Grant P01-HD31921 from the Eunice Kennedy Shriver National Institute of Child Health and Human Development, 
with cooperative funding from 23 other federal agencies and foundations. Special acknowledgment is due to Ronald R. Rindfuss and Barbara Entwisle for assistance in the original design. Information on how to obtain the Add Health data files is available on the Add Health website (http://www.cpc.unc. edu/addhealth). No direct support was received from Grant P01-HD31921 for this analysis.

\section{Authors' contributions}

HS conceived of the study and drafted the manuscript; CAV conceived of the study and helped to draft the manuscript as well as approved the final version; SSBF conceived of the study and reviewed drafts as well as approved the final version; RD conceived of the study and reviewed drafts as well as approved the final version; ELT conceived of the study and performed analyses as well as helped to draft the manuscript; JB conceived of the study and performed analyses as well as helped to draft the manuscript. All authors have read and approved the final version of the manuscript, and agree with the order of presentation of the authors.

\section{Competing interests}

The authors declare that they have no competing interests.

\section{References}

1. Skinner AC, Skelton JA. Prevalence and trends in obesity and severe obesity among children in the United States, 1999-2012. JAMA Pediatr 2014;168:561-6.

2. Ogden CL, Carroll MD, Kit BK, Flegal KM. Prevalence of childhood and adult obesity in the United States, 2011-2012. JAMA 2014;311:806-14.

3. Jain A. Fighting obesity: evidence of effectiveness will be needed to sustain policies. BMJ 2004;328:1327. doi:10.1136/bmj.328.7452.1327

4. U.S. Department of Health and Human Services and Office of Disease Prevention and Health Promotion. 2008 Physical activity guidelines advisory committee report. Washington, DC: U.S. Government; 2008.

5. Chaudhari K, Wong JM, Vann PH, Sumien N. Exercise training and antioxidant supplementation independently improve cognitive function in adult male and female GFAP-APOE mice. J Sport Health Sci 2014;3: 196-205.

6. Kann L, Kinchen S, Shanklin SL, Flint KH, Kawkins J, Harris WA, et al. Youth risk behavior surveillance-United States, 2013. MMWR Surveill Summ 2014;63(Suppl. 4):S1-168.

7. Herman KM, Craig CL, Gauvin L, Katzmarzyk PT. Tracking of obesity and physical activity from childhood to adulthood: The Physical Activity Longitudinal Study. Int J Pediatr Obes 2009;4:281-8.

8. Caspersen CJ, Pereira MA, Curran KM. Changes in physical activity patterns in the United States, by sex and cross-sectional age. Med Sci Sports Exerc 2000;32:1601-9.

9. Gordon-Larsen P, Nelson MC, Popkin BM. Longitudinal physical activity and sedentary behavior trends: adolescence to adulthood. Am J Prev Med 2004;27:277-83.

10. Han J, Dinger MK, Hull HR, Randall NB, Heesch KC, Fields DA. Changes in women's physical activity during the transition to college. Am J Health Educ 2008;39:194-9.

11. Bois JE, Sarrazin PG, Brustad RJ, Trouilloud DO, Cury F. Elementary schoolchildren's perceived competence and physical activity involvement: the influence of parents' role modelling behaviours and perceptions of their child's competence. Psychol Sport Exerc 2005;6:381-97.

12. Cleland V, Timperio A, Salmon J, Hume C, Telford A, Crawford D. A longitudinal study of the family physical activity environment and physical activity among youth. Am J Health Promot 2011;25:159-67.
13. Oetzel JG, Ting-Toomey S, Rinderle S. Conflict communication in contexts: a social ecological perspective. In: Oetzel JG, Ting-Toomey S, editors. The SAGE handbook of conflict communication: integrating theory, research, and practice. Thousand Oaks, CA: Sage; 2006.

14. Adams-Campbell LL, Rosenberg L, Washburn RA, Rao RS, Kim KS, Palmer J. Descriptive epidemiology of physical activity in African-American women. Prev Med 2000;30:43-50.

15. Evenson KR, Wilcox S, Pettinger M, Brunner R, King AC, McTiernan A. Vigorous leisure activity through women's adult life: the Women's Health Initiative Observational Cohort Study. Am J Epidemiol 2002;156:945-53.

16. Scharff DP, Homan S, Kreuter M, Brennan L. Factors associated with physical activity in women across the life span: implications for program development. Women Health 1999;29:115-34.

17. Ornelas IJ, Perreira KM, Ayala GX. Parental influences on adolescent physical activity: a longitudinal study. Int J Behav Nutr Phys Act 2007;4:3. doi:10.1186/1479-5868-4-3

18. Phillips JA, Young DR. Past-year sports participation, current physical activity, and fitness in urban adolescent girls. J Phys Act Health 2009;6:105-11.

19. Trudeau F, Laurencelle L, Shephard RJ. Tracking of physical activity from childhood to adulthood. Med Sci Sports Exerc 2004;36:1937-43.

20. Melinda JC, Symons C, Zimmermann JAM. Why do young women drop out of sport and physical activity? A social ecological approach. Ann Leis Res 2009;12:148-72.

21. Boone-Heinonen J, Gordon-Larsen P. Life stage and sex specificity in relationships between the built and socioeconomic environments and physical activity. J Epidemiol Community Health 2011;65:847-52.

22. Gordon-Larsen P, McMurray RG, Popkin BM. Determinants of adolescent physical activity and inactivity patterns. Pediatrics 2000;105:E83.

23. Basterfield L, Adamson AJ, Frary JK, Parkinson KN, Pearce MS, Reilly JJ. Longitudinal study of physical activity and sedentary behavior in children. Pediatrics 2011;127:e24-30.

24. Hearst MO, Patnode CD, Sirard JR, Farbakhsh K, Lytle LA. Multilevel predictors of adolescent physical activity: a longitudinal analysis. Int $J$ Behav Nutr Phys Act 2012;9:8. doi:10.1186/1479-5868-9-8

25. White JL, Ransdell LB, Vener J, Flohr JA. Factors related to physical activity adherence in women: review and suggestions for future research. Women Health 2005;41:123-48.

26. Craggs C, Corder K, van Sluijs EMF, Griffin SJ. Determinants of changes in physical activity in children and adolescents. Am J Prev Med 2011; 40:645-58.

27. U.S. Department of Health and Human Services. Healthy People 2020: Physical Activity. Available at: http://www.healthypeople.gov/2020/ topicsobjectives2020/objectiveslist.aspx?topicId $=33 ; 2012$ [accessed 01.03.2013].

28. Harris KM, Halpern CT, Whitsel E, Hussey J, Tabor J, Entzel P, et al. The national longitudinal study of adolescent to adult health: research design. Available at: http://www.cpc.unc.edu/projects/addhealth/design; 2009 [accessed 30.10.2014].

29. Sheehan TJ, Fifield J, Reisine S, Tennen H. The measurement structure of the Center for Epidemiologic Studies Depression Scale. J Pers Assess 1995; 64:507-21.

30. Hoyt LT, Chase-Lansdale PL, McDade TW, Adam EK. Positive youth, healthy adults: does positive well-being in adolescence predict better perceived health and fewer risky health behaviors in young adulthood? $J$ Adolesc Health 2012;50:66-73.

31. Sallis JF, Prochaska JJ, Taylor WC. A review of correlates of physical activity of children and adolescents. Med Sci Sports Exerc 2000;32:963-75.

32. Telama R, Yang X, Viikari J, Välimäki I, Wanne O, Raitakari O. Physical activity from childhood to adulthood: a 21-year tracking study. Am J Prev Med 2005;28:267-73.

33. Jakicic JM, Rogers RJ. Physical activity for weight maintenance, weight loss, and prevention of weight re-gain. Available at: https://www. presidentschallenge.org/informed/digest/docs/201306digest.pdf; 2013 [accessed 01.06.2014].

34. Piazza-Gardner AK, Barry AE. A qualitative investigation of the relationship between consumption, physical activity, eating disorders, and weight consciousness. Am J Health Educ 2014;45:174-82. 
35. Sherwood NE, Jeffery RW. The behavioral determinants of exercise: implications for physical activity interventions. Annu Rev Nutr 2000;20:21-44.

36. Deforche BI, De Bourdeaudhuij IM, Tanghe AP. Attidude toward physical activity in normal-weight, overweight and obese adolescents. J Adolesc Health 2006;38:560-8.

37. Hagger MS, Chatzisarantis NL. Integrating the theory of planned behaviour and self-determination theory in health behaviour: a meta-analysis. Br J Health Psychol 2009;14:275-302.

38. Jaakkola T, Washington TL. Measured and perceived physical fitness, intention, and self-reported physical activity in adolescence. Adv Phys Educ 2011;1:16-22.

39. Huotari P, Sääkslahti A, Watt A. Associations between the self-estimated and actual physical fitness scores of Finnish Grade 6 students. Facta Univ Phys Educ Sport 2009;7:27-36.

40. Genkinger JM, Jehn ML, Sapun M, Mabry I, Young DR. Does weight status influence perceptions of physical activity barriers among African-American women? Ethn Dis 2006;16:78-84.

41. Centers for Disease Control and Prevention. Facts about physical activity. Available at: http://www.cdc.gov/physicalactivity/data/facts.html; 2012 [accessed 01.03.2013].

42. Seabra A, Mendonca D, Maia J, Welk G, Brustad R, Fonseca AM, et al. Gender, weight status and socioeconomic differences in psychosocial correlates of physical activity in schoolchildren. J Sci Med Sport 2013; 16:320-6.
43. Biddle SJH, Whitehead SH, O'Donovan TM, Nevill ME. Correlates of participation in physical activity for adolescent girls: a systematic review of recent literature. J Phys Act Health 2005;2:423-34.

44. Boone-Heinonen J, Diez Roux AV, Kiefe CI, Lewis CE, Guilkey DK, Gordon-Larsen P. Neighborhood socioeconomic status predictors of physical activity through young to middle adulthood: the CARDIA study. Soc Sci Med 2011;72:641-9.

45. National Association for Sport and Physical Education. Physical education is critical to educating the whole child (Position statement). Reston, VA: Author; 2011.

46. Physical Activity Guidelines for Americans Midcourse Report Subcommittee of the President's Council on Fitness, Sports \& Nutrition. Physical Activity Guidelines for Americans Midcourse Report: strategies to increase physical activity among youth. Washington, DC: U.S. Department of Health and Human Services; 2012.

47. Centers for Disease Control and Prevention. Strategies to prevent obesity and other chronic diseases: The CDC Guide to Strategies to Increase Physical Activity in the Community. Atlanta, GA: U.S. Department of Health and Human Services; 2011.

48. Donnelly JE, Lambourne K. Classroom-based physical activity, cognition, and academic achievement. Prev Med 2011;52(Suppl. 1):S3642 .

49. Roman CG, Chalfin A. A fear of walking outdoor. A multilevel ecologic analysis of crime and disorder. Am J Prev Med 2008;34:306- 